\title{
Sexual Violence of Adolescents: What Specificity?
}

\section{Savinaud C*}

Professor of Clinical Psychology and Psychopathology, Catholic University of the West UCO Angers, France

*Corresponding author: Savinaud C, Teenage psychoanalyst, former professor of clinical psychology and psychopathology at IPSA- Catholic University of the West UCO Angers,

\section{Research Article}

Volume 5 Issue 2

Received Date: September 24, 2021

Published Date: October 05, 2021

DOI: $10.23880 / \mathrm{mhrij}-16000151$ associate member of the research team in clinical psychology (EPC), 8, route de Missé Maulais 79100 Plaine Et Vallees, France, Tel: +33549662943; Email: claude.savinaud@wanadoo.fr

\section{Abstract}

Cases of sexual abuse of adolescents are not limited to behaviors classified according to their inadequacy to social reality and their adaptive capacity. Our study covers 60 cases of adolescents followed for 10 years in psychotherapeutic care, 32 of which were analyzed according to an evaluation grid based on nosographic criteria derived from the classical psychopathology used in Europe and South America. (Freudo-Lacanian designs). From this statistical and empirical analysis, we conclude that the assaults of adolescent perpetrators of sexual abuse have significantly different characteristics, not in behavioral terms in relation to the age of the perpetrator or the victim, the socio-cultural context, or in the mode of operation, but in terms of intrapsychological and developmental issues. We have distinguished 3 «psychopathological categories »: archaic functioning, rivalry « mirrored » infant positions, and violent genital organizations, in relation to chaotic, symmetrical parental-adolescent familial dueling relationships, and finally grounded in transgenerational guilt. The distribution of cases according to these criteria gives balanced results from the point of view of the designated categories, which supports the hypothesis of a graduation of the problems according to the combination of the different psychic organizations in the fields of their agic expression, the forms of underlying sexualities, and family structures. They are subject to an action psychopathology that takes into account their position in relation to the childhood history of their sexuality and the novelty of Pubertaire's issues, which can be traumatic. Our clinical approach, of psychoanalytic orientation, allows us to better seriate the psychic processes in progress in the expression of sexual violence, and to propose a dynamic reading grid.

Keywords: Adolescence; Sexual Abuse; Family; Puberty; Specularity

\section{Introduction}

Our study is based on a cohort of 32 clinical cases of adolescents who commit sexual assaults. The cohort is drawn from a population of about sixty teenagers who were received between 2000 and 2009 in a specialized consultation of a University Service of Infant and Juvenile Psychiatry. This outpatient consultation was created to meet the demand of the Justice Services, the Youth Judicial Protection (YJP), but also educational teams of schools or schools for the disabled (I.M.E.), medical-educational teams of care structures, or reception of victims, and finally general practitioners and families. The team dedicated to this reception was composed of psychiatric doctors, psychologists, psychotherapists of various backgrounds, and specialized educators. The project was to propose an evaluation and follow-up of adolescents as soon as the facts were reported, without delay and taking into account the judicial indication of the care in its specificity. Given the complexity and diversity of the situations encountered, the team sets itself the objective of meeting all the stakeholders with the adolescent for a preliminary exploration, and the establishment of multifocal 


\section{Mental Health \& Human Resilience International Journal}

psychotherapeutic management adapted to each case. Sexual abuse in adolescents is defined as obtaining such satisfaction without the consent of the partner.

It is obtained by violence or coercion, physical or psychological. There are many shapes: visual exposure (exhibitionism, pornography), touching or sexual performance (rape or attempted rape by penetration). It is distinguished from the exploratory sex games of the child period and the accession to puberty, by this desire to control the victim. Like many other authors [1,2], we ask ourselves the question of the need to establish a logical relationship between the sexually violent act and the psychological and social characteristics of the adolescent sexual abuser. Can there be a relationship between the type of act and a particular problem of the individual, related to his age, personality traits or socio-cultural situation?. After our initial clinical investigations, our first question concerned the relationship between the age of the perpetrator and that of the victim, the seriousness of the acts and the socioeducational context. We have established the empirical finding that the characterization of acts of sexual assault cannot be combined with a specific personality type or a particular biography having the value of an exclusive explanation, for adolescents. Our study tends to explain this finding and draw the consequences.

\section{Results of the Survey of Our Active Queue of Teenagers who are Sexually offenders}

Predictably, and consistent with similar studies, this cohort is almost exclusively male adolescents (58/60). Only two girls are in this group and their particularity does not significantly alter the overall results.

\section{Ages of Adolescents who Commit Sexual Assault}

We have divided our sexual assault population into three age groups that correspond:
1. to prepubescent children $9-11$ years 2

2. pre-teens: $12-14$ years 21

3. teens: $15-17$ years 37

Total 60

If we take into account the two pre-teens already mentioned in the column of 12-14 years, we find that there are $1 / 3$ of pre-teens who commit sexual violence, and $2 / 3$ of adolescents.

The fact that there are no or very few prepubescent children $(<11$ years) who commit sexual violence can be attributed to the (health) recruitment method, but also to the fact that public and professional awareness of this emerging problem of uneducated children and perpetrators of sexual assault has been reduced compared to the current situation in the period 2001-2009.

\section{Ages and Gender of Victims of Sexual Assault}

We divided the victims into 5 categories, corresponding to the different ages of life. The first category of infant, up to 4 years old, is quite artificial because it corresponds to only one case of child pornography in which images of very young children were exchanged. Only one item of victim per gender was selected, so as not to increase the victim/perpetrator ratio. This is the only case where children of this age were involved in the imputation of sexual assault of a teenager. The other 4 categories: 4-8 years, 9-12 years, 13-17 years, adults, correspond to a priori delimitations of positions in relation to sexual maturation: the infant period, the period of latency, adolescence, and adulthood. Each has specific characteristics, but the boundaries between them may seem arbitrary. It is particularly interesting to note that there are two " peaks » in the frequency of victimization, one major for the infant period (27) and the other for the adolescent period (15), separated by a trough corresponding to the latency period (Table 1).

\begin{tabular}{|c|c|c|c|c|}
\hline Age des victimes & Masculin & Féminin & Non connu & Total \\
\hline moins de 4 ans & 1 & 1 & & 2 \\
\hline 4-8ans & 3 & 10 & 2 & 14 \\
\hline 9-12 ans & 6 & 6 & 5 & 15 \\
\hline 13-17ans (ados) & & 10 & 1 & 3 \\
\hline adultes & & 2 & 2 & 5 \\
\hline non connu & 10 & 3 & 24 & 66 \\
\hline total & & 32 & 24 & \\
\hline
\end{tabular}

Table 1: Recapitulation of victims ages according to their gender chart. 


\section{Mental Health \& Human Resilience International Journal}

\section{Age Comparison of Perpetrators and Victims of Sexual Assault}

Reduced to a percentage of the total population, they show a disparity between age groups. Infant victims may appear to be particularly vulnerable due to their immaturity (40\%), and adolescents may be more willing to act as they grow up (62\%) (Figure $1 \&$ Table 2).

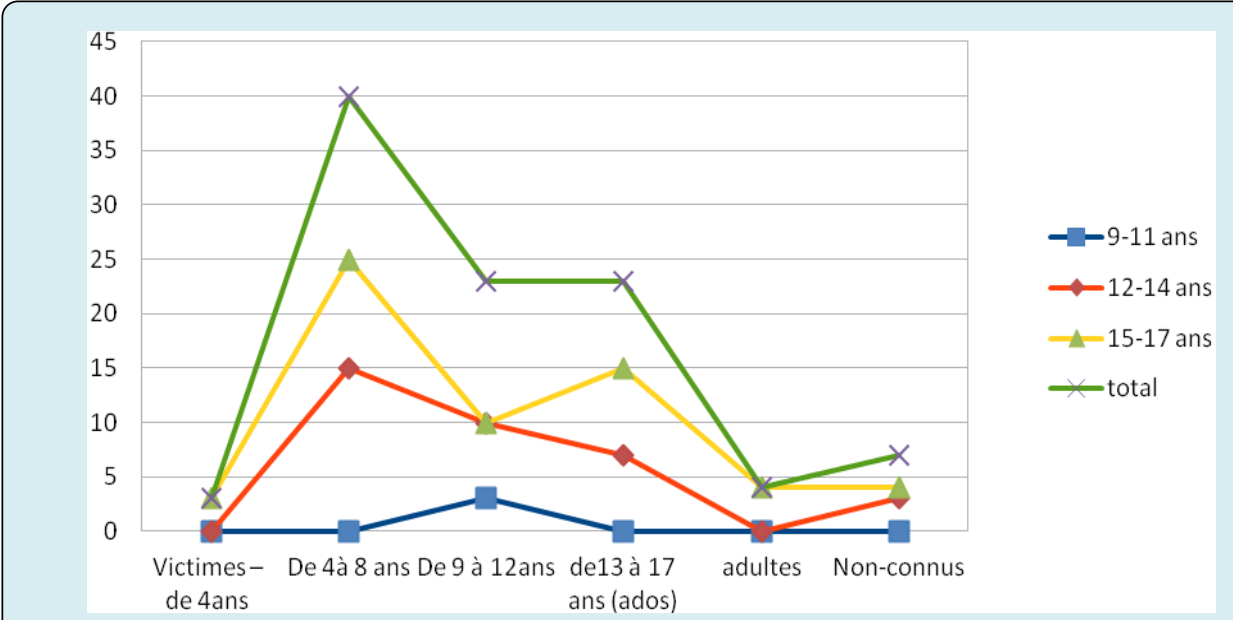

Figure 1: Percentage of victim ages according to offender ages comparative diagram.

\begin{tabular}{|c|c|c|c|c|c|c|c|}
\hline age de I'agresseur & Victimes-4ans & De 4 a 8ans & De 9 a 12ans & De 13-17 ans (ados) & adultes & non connus & total \\
\hline 9-11 ans & & & .03 & & & & .03 \\
\hline 12-14ans & & .15 & .10 & .07 & & .03 & .35 \\
\hline 15-17ans & .03 & .25 & .10 & .15 & .04 & .04 & .62 \\
\hline total & .03 & .40 & .23 & .23 & .04 & .07 & $100 \%$ \\
\hline
\end{tabular}

Table 2: Percentage of victim ages according to offender ages comparative chart.

But a close examination, highlighted by comparisons between vulnerability curves, shows that adolescents $(60 \%)$ and especially preteens (80\%) exercise their sexual violence on significantly younger children, of both sexes. The number of victims « boys » reached its maximum and equalized with the " girls » during the period 9-12 years, to disappear in adolescence proper. It may be considered usual for a violent subject to attack someone smaller than him, but one may wonder about the type of sexual satisfaction sought with an immature being. This primacy in the choice of victims of the infant period corresponds perhaps to a facilitation of the hold, heralding a psychopathic " orientation» of the personality. But we could also mention the psychic regression to a child position as a dynamic factor in the expression of sexuality through aggression, because it results from a blockage in the accession to sexual maturity and the recognition of the difference of the sexes. This "regressive » can also be attributed to more fundamental barriers to sexuality in the relationship with others and in family structure. Therefore, we will continue to analyze this issue by studying more precisely the psychic processes at work in these relational and family dimensions of sexuality.

\section{To Explore Violent Sexual Conduct Otherwise}

\section{Presentation of a Multimodal Reading Grid on Sexual Violence}

"Logical Matrix»: Starting from the psychic issues of adolescence, which cannot be addressed independently of family functioning and the place of the adolescent in this functioning, we have chosen three dimensions to explore these situations: construction of sexuality, family functioning and nature of the act. The application of the logic matrix makes it possible to describe, analyze and evaluate the main characteristics of the situations encountered. It also allows us to move from logic of differentiating acts according to the usual objective criteria in criminology, to focus on the specificity of the underlying psychic and collective dynamics [3]. 


\section{Mental Health \& Human Resilience International Journal}

\begin{tabular}{|c|c|c|c|}
\hline & Act & Sexuality & Family \\
\hline $\begin{array}{c}\text { Secondary (Symbol) Terciary (C.S } \\
\text { Pierce) }\end{array}$ & $\begin{array}{l}\text { Aggressive (neurotic) } \\
\text { acting out }\end{array}$ & $\begin{array}{c}\text { Oedipal markers } \\
\text { installed } \\
\text { - guilt } \\
\end{array}$ & $\begin{array}{l}\text { «Normal } », \text { rules beyond the } \\
\text { family < socius }\end{array}$ \\
\hline $\begin{array}{c}\text { Intermediate (Icon) secondary (CS } \\
\text { Pierce) }\end{array}$ & $\begin{array}{c}\text { Violence with one address } \\
\text { to another } \\
\text { «mirrored» }\end{array}$ & $\begin{array}{l}\text { Infantile, preoedipal, } \\
\text { partial impulses }\end{array}$ & $\begin{array}{c}\text { Imaginary, autarkic working in } \\
\text { Duel mode }>\text { socius }\end{array}$ \\
\hline Primary (Object) native & $\begin{array}{l}\text { Direct, discharge, action } \\
\text { or recourse to the act of } \\
\text { disconnection }\end{array}$ & $\begin{array}{l}\text { Archaic, pre-objective, } \\
\text { on a background of } \\
\text { emotional emptiness, } \\
\text { loss of bond. }\end{array}$ & $\begin{array}{c}\text { Chaotic, deconstructed } \\
\text { Unpredictability, trauma Real \# } \\
\text { socius }\end{array}$ \\
\hline
\end{tabular}

In a first approximation, we considered that each of the registers has 3 operating levels:

- A primary level (or originating) that calls upon the movement « reflex » the organic response to a sexual stimulus, below any psychic representation, any differentiation

- An intermediate level, in which it is the function of the image that dominates the sexual relationship, with the instability of this mode of representation based on form, external appearance and its fleeting appropriateness to the interiorized figurability of the object.

- A secondary level where the object is named before being invested, on a mode of elaboration of the distance which favors the word over the act, the associations of prevalent ideas over the sensory tested, the dimension of the forbidden regulating the relation to the object.

These distinctions may seem abstract and difficult to make at first glance. But they are extracted from a clinical experience of psychopathological expression which differentiates the modes of symptomatic expression according to processes internal to the psychism, according to psychoanalytic conceptions. They can be found at work in differentiated nosographic tables as in the everyday expression of psychic life. Far from being mere empirical data of the observation from which they derive, they " function » in a psychoanalytic understanding of the psychic apparatus which calls upon various and confluent sources of its conceptualization.

Tierceity and Its Post-Freudian Avatars: The genesis of the steps that underlie the emergence of a Subject presupposes a logic both temporal but also structural of a precession of processes on others, which anticipate the new elements to come. The idea of a developmental continuum between childhood and adulthood does not favor the distinction of pathogenesis effects related to these stages unless it is noted that some have been skipped, others have not been reached, or that backsliding caused by particular post-stage difficulties is a retropredictive hypothesis. It is known that the Freudian division between the oedipal repression and the " afterthought » which characterizes human bi-phasic sexuality makes adolescence a procedure for reshaping essential narcissistic and objective investments. At least we can count on this qualitative and quantitative leap to examine what happens in sexuality which is not the mere continuation of the problems encountered previously. What seems to be emerging «, in addition to the » of childhood polymorphic sexuality, is under allo-erotic instinct, the return of « primary processes « posthumous » [4] and, at the same time, the establishment of a thought (in the broadest sense of the term) that is not simply the renewal of the relationships experienced during previous periods of exploration and learning of the basic patterns.

Hence the idea of redesigning psychic events according to a new trilogy «borrowed »from the semiology of C. S. Peirce [5], but in the continuity of Freud: primarity concerns the investment of the object itself, in its concreteness and immediacy, secondarity presupposes an object relationship, the emphasis being placed not on the object but on this relationship, which becomes the mode of communication of the affects aroused by the investment, finally the need to make room for a tiercity, relations between relations, a concept based on the third dimension introduced by the symbolism between the desired subjects, and whose absence or partial failure would signal the subjective position of the «borderlines » [6]. The contemporaneity of this nosographic entity and the consideration of the specific adolescent processes of which they constitute the normal developmental model will be emphasized. Pierce distinguishes three registers within the communication: the Real, that is to say the register of the object in its own qualities, the index or sign that represents the object for someone, and the interpreter, that connects the signifiers between them. A signifier represents the subject in relation to another signifier. We can accentuate this level differentiation between Thing, Icon and Symbol. The iconic register functions as a signal that indicates the presence in the absence of the Thing represented, and therefore the trace of the one that indicates this presence, the register of the signifier is valid as an element in the absence of trace (negation of the negation) as a message addressed to another 


\section{Mental Health \& Human Resilience International Journal}

Subject, enigmatic but inscribed in the language chain.

\section{The Transgressive Sexual Agirs Clinic}

Without going any further into the explanation of this tripartition and taking over the authors who have allowed this new topic, we drew on these three levels to distinguish in the acts, sexual practices and family organizations three registers corresponding to different organizations: It will be assumed that the assumption that human acts are not only intended to appropriate objects from the environment for utilitarian purposes, but also reflect a certain way of escaping an internal imbalance, which can be called: anxiety, but not more precisely. The actions are the driving expression of a psychic tension which can then take on particular meanings, depending on whether they respond essentially to the elimination of this tension, or whether they reflect a deadlock in the elaboration of a conflicting thought about this tension, source of anxiety. The acts are therefore to be distinguished according to a graduation which goes from the direct discharge of the tension, to the most secondary form as the symbolic " act ». To the extent that it arises from a situation where subjectivity and the place of the other are questioned, sexual tension presents an isogeny in relation to anxiety. (Same physiological characteristics, same symptoms). Hence the hypothesis of linking anxiety and « sexual » act, whether it be the discharge of pure violence, the gesture of stealthy caress designating the protruding tip of the emergence of desire or the stumbling of an emotion poorly contained in a significant internal distress), passing through the violently externalized expression of an identity malaise addressed however to another identifiable, although little differentiated).

This tripartition would be roughly equivalent, respectively, to the Lacanian registers of the Real, the Imaginary and the Symbolic [7], knowing that none is worth in itself if it is not attached to the others, in a particular knotting that designates the psychopathological mode of its articulation. Let us add that there may be pure « cases» where a single dimension affects these three registers of the nature of the act, the modes of underlying sexualities and the social and family configurations in which it intervenes as resolute «phase» anguish. However, cases of figures can be declined at several levels, making the combinatorics operational to decrypt ad libitum a clinic of the multidimensional act. It would even be essential to explore the possible commutations, to avoid giving the impression that an act would signify belonging to a homogeneous functioning in the three registers of its effectiveness, the sexuality it translates and the family and social structure on which it depends, this in order to avoid causal deductions (e.g.: chaotic family, rough sexuality and brutal act).

\section{CASE Stephen (The Clinical Case Is Voluntarily Reduced To the Clues Allowing It to Be Located In the « Reading Grid »)}

Stephen is a 15-year-old who has practiced repeated reciprocal fellations for several months or a year successively on his two half-brothers aged 7 and 11 . He was discovered by his mother, who expressed her dismay, as she herself had been touched by her family, and blamed herself for not reacting earlier to certain signs. Stephen presents the facts as sexual games accepted and solicited by his $1 / 2$ brothers, without guilt but with the claim of shared responsibility, including with the mother who prevents him from going out at night with friends of his age outside. (HLM city).

" I canst find anything to do at home, it pisses me off, I can't even get the video games and internet to myself. »

Current educational difficulties (absenteeism) are also mentioned, in contrast to the image of a wise and cooperating child during childhood. Since joining college, Stephen has been vocal in his opposition to adult laws. He readily sarcastically talks to teachers, considering that his provocations are a game in which the adult agrees or not to enter. Most of all, he is outraged by the authority of this father-in-law, who " is completely out of touch with youth, refuses to talk and punishes without understanding. It's over that time! »

The mother admits " protecting » son from the stepfather's attempts at punishment, "I don't want him to touch him, the others yes, but not him ». She obviously agrees with Stephen that he is " clogged, he understands nothing ", whereas she, until now, managed to be obeyed after fierce discussions and haggling with her son, concerning for example his nocturnal frequentations which worry him. To avoid « that it goes out too much, to the detriment of the duties», she accepts good grè-mal grè, the compulsion to share " his » computer with Stephen who evokes " his » birthright to dispose of it according to his pleasure, and without control of his «contacts » on the WEB.

Stephen, in interview alone, indicates that he understood his actions that revealed to him his " bi-sexuality ». He considers that a measure of removal from the home would be an unacceptable violence, the consequences of which his mother would later have to bear.- « So, if I am forced to go far from home, you are not close to seeing me again! What will happen to me will be your fault... » These few elements illustrate the identification of the act rather in the advent of a homophilic pubescent sexuality claimed as a freedom to have a sexuality out of maternal control (the act would be situated as secondary to an infantilization by the mother, in an attempt to elaborate a subjectal version of puberty: exiting childhood 


\section{Mental Health \& Human Resilience International Journal}

sexuality by a «acting-out» which induces the Other maternal to interpret this new position regarding sexuality). On the other hand, the modalities of genitality seem to obey partial (oral) impulses, aiming at an inadequate object (sibling) on the mode of immaturity and avoidance of Oedipal conflict, but rather in a rivalry and exclusive position (intermediate level). Finally, we can perceive in the maternal attitude one duel functioning marked by fascination for the watereddown image of the rebellious adolescent, in opposition to the paternal or social third guarantor of the law. She blocks this authority in the name of a fantastic filiation that puts her son in an exceptional position. She associates it with the story of one of her own brothers, a homosexual, whom she felt close to and in revolt against the incomprehension and violence of their own father.

\section{The Organization of Sexuality (The Future of the Sexual)}

It should describe three conditions of sexual intercourse: genital (under construction); infant (more or less subjected to castration and the primate of Phallus) and pregenital, still invaded by autoeroticism, or pre-objectal, body to body, sensoriality. The mode of " sexuality » contained in the act can be of the order of the archaic, located in the infra-sexual as overflow of the instinct in the raw state. In the register of childhood, he favors pre-genital modes of expression of sexuality in an attempt to merge with the object of investment. Finally, the " of the Oedipal » of sexuality introduce gender difference and the primacy of the genital. To try to account for this clinic through the concepts implemented in this « reading grid », we can rely on the data of the singular history of the " cases » [8] and the findings of a multiform operativity of this « sexual » violence, or so-called.

The «Infantile»: We have often perceived a form of envious relationship with victims, whether they are relatives or surrogates. This proximity, one could say emotional promiscuity, plunges aggression into a climate of « specularity » in the sense that Lacan gave it in the mirror relationship. The subject and the other are confused in an image whose alienating reflection dispossesses the subject of the object of his desire. This reversible image of an object of love and hatred contains the other and oneself in effigy, and the act may resemble a crossing of the mirror to join the objectoneself (narcissistic) of which the subject feels dispossessed, in a persecutory mode.

This configuration can be established as a simple transversal displacement of a dueling relationship exclusive to the mother, who seeks in the child the reflection of his lack of being, and finds in the adolescent the "all-other " that puberty brings out on the background the denials of his own sexuality. But it may also be the result of a logical time of taking a protective position with respect to this alterity of the pubertal object which awakens the resurgence of an original dereliction, in the absence of accentuated features of the relationship of control between the parent and the child. We are therefore confronted with a mirror relationship, imaginary, whose processes are part of the Algarganian Primarity, where the victim signals what someone lacks, whether this lack limits the gaping of the body image opened by pubertal break-in, or whether it emerges as a trace of the impossibility for the actor to find in the mother's gaze this recognition beyond the fantastic object that it is for her, and thus is damaged in the vision of the other as an unbearable refraction of his own lack.

The cases of figures encountered may be based on the failure (by default or by excess) of the Third Party (paternal or maternal) to be inscribed as a separator in this mortifying reflexive duality, but also on the fact of imaginary inscriptions superimposed by " transgenerational stories » life (death, sterility, adoption, sexual or moral faults of the previous generation, etc.) which weave the interpretation of the advent of adolescent sexuality of incestuous bonds not said because excluded from the parental psyche. Sometimes, it is even more the absence of repression of these residues of child or transgenerational prehistory that marks teenage sexuality with a trace of Real, like « bulky but unavoidable » corpses that the adolescent must straddle to follow his path.

«Genital»: In rare cases, we have also encountered forms of action that could demonstrate the prevalence of secondary processes related to oedipal guilt. It seemed to precipitate the subject to « fault » to better restore the place of the forbidden, to give it a consistency undermined by the emergence of desire. We think of a few cases where " aggression " was in fact a game of mutual seduction where the teenager experienced his new sexuality as a " toy » a little excessive in relation to his capacity of containment, even a revelation of a homosexual tendency or desire felt as a well-founded affirmation of a mature object choice but in violation of the parental norm. The Social Third (justice, parents...) who is challenged through criminal conduct relieves the subject of a feeling of guilt floating to orient him in the problem of castration by focusing the anguish on the punishment " release ». It can be considered that this Tierceity is already included in the problem, even if the act designates the need for a redefinition of the interpreter according to the new sexual situation engaged by puberty. It can, however, function as a trauma, Real, that is to say as the trace of an event not yet symbolized which pierces the signifying chain and leaves a hole in the Symbolic, reiterating the enigma of the enjoyment of the Other and momentarily restoring to the body its status as a fragmented object, of tessels of organs without functional unity, taken in this enjoyment. This last point is in transition with the last case. 


\section{Mental Health \& Human Resilience International Journal}

"Archaic": Finally, one can be confronted in the clinic with the emergence of » primary « processes, not in the Freudian sense of the term but in a Peircian sense of a crude fact, which the subject is seized with in an inaugural moment of its existence. Lived intensely as the submersion of a " enjoyment of himself ignored » (cf: rat man [9]), it appears in the aftermath as the zero degree of thought invaded by the hallucinatory process or in a twilight aura confining to a state of psychic death. This confrontation with death, as it is at the end of life as well as at the beginning, is not alien to the situation of adolescence, which involves the supports of previous identifications and transforms the Identified person into a stranger « who can only preserve the link that connects him to the Identified person because he becomes the intruder, the enemy that we will try to destroy » [10]. This metabolism of hatred by the primordial object is indeed what is in the «beginning», but our experience shows us that it does not disappear completely with the implementation of secondary refoulement. It remains encysted, either because the primary return is never completely acquired, there is a remainder, or because the pictographic representation of the erogenous zone-object of satisfaction finds in the genitality a proposal of reductive completeness of the ruptures caused by the earlier separations, or again because the sexual fantasy is not sufficient to propose a framework resolving this impossible conjunction.

In any case, a self-generated thought keeps in a cleavage a «I » that takes into account the Real and another «I ", plagued by the temptations of the world's negation; cleavage of a «I Iidentifier, omnipotent and a «I » identified stereotyped, fossilized in an idealization of himself, the instinctive object or the ideals of group and social death. But these morbid processes are not frozen and may be secondary to a de-idealization of both the identifying function and the identifying statement. This work makes it possible to escape from the totalitarian discourse of the Almighty Other to forge the bases of an identification with a personal project, from the emblems borrowed from culture that inscribe it in the difference of the sexes and generations.

\section{The Family Dimension}

In his encounter with the other the young child is immediately confronted with deprivations, threats, assaults, in fact « lack ». In order for this confrontation to be positive, a number of conditions must be met, conditions linked to the dynamics of the family group in which the child develops, because " reducing childhood pathology to the influence of traumatic events occurring in childhood leads to " oversimplification. Also at stake is how these events will be assimilated, transformed or even used as materials for the construction of the subject [11].
Beyond the recurrent denunciations of the disappearance of the father and the omnipotence of the mother, it is for us to specify the benchmarks allowing us to characterize the functioning of the family with regard to the dimensions listed above. The family can be defined as the place where the child then the adolescent acquires, and then implements, in the first humanization work, the generational difference and the sexual difference. The family also has a function both of transformation and transmission of these dimensions, but also of their translation into social relations.

In this register we have retained a triple distinction:

1. Chaotic « relations » indifferentiation.

2. Organizations «mirrored», with the effects of suggestion, subjugation on a duel mode. Object and subject are distinguished but one is the other's upside...world where projection and primary identification reign: «it's him or me» [12].

3. Finally, the normative or normative structure based on the law as a third dimension intervening in mediation in the expression of sexuality, based on the functioning of language. This division, which results from a mix between systemic categories and more psychoanalytic conceptions of intra-family dynamics (e.g.: stage of the mirror), seems to be able to account for a variability of the educational substrate by focusing on structural modes that have an impact on psychic construction.

To use these three levels of functioning, we can describe as chaotic relationships situations where the child can never know how the adult, the other will react, putting the subject in a state of anxious bewilderment or permanent expectation of danger. But they can also result from the impossibility of predicting punishment for one's actions, by the emotional indifference or incoherence of references to social norms, whether rigid or on the contrary lax. Thus, this notion is relatively independent of the socio-economic and cultural characteristics that are generally incriminated in these situations.

The dueling, mirrored relationships, also called " symmetrical escalations » by the Systemicians, characterize situations of permanent confrontation, or on the contrary of the imaginary assimilation of the child to parental fantasies, whether these are idealized or directly realized through the body of the child. Characteristic of the movements of influence, they are part of the permanent narcissistic seductions that can eventually be transposed on the plane of the accession to sexuality. But the child can also take control of it by blending with the image projected on him, or by exerting pressure on the adult fascinated by his own imagination (cf: Stephen case). 


\section{Mental Health \& Human Resilience International Journal}

Triangular relations, considered normative because they introduce the markers of social prohibition, can also contribute to disturbances of the relation to the object, since they introduce, in fact, the inhibition of the pressure of desire, resulting in its ignorance and its resurgence in debilitating symptomatic forms. Thus, hyper-rigidity can also be a factor blocking the child's accession to pubescent sexuality, which is inherently transgressive. This is all the more so since it can hide behind agreed and complacent figures of parenthood and translate psychic conflicts that have remained unelaborated in the family [13].

If we divide our cohort into the headings of this new grid, we get their grouping into a typology of pure « cases », homogeneous in all dimensions:

- Of primary type: (6 cases) where the disconnection of erotic and aggressive impulses (Type I " pure ») responded to anxiety of neantization or depression fueled by brutal bodily changes linked to puberty or other factors of psychic disorganization, in a context of failure of parental support in the reconstruction of childhood traumas or deficiencies updated by pubertal sexuality.

- Of secondary type: (6 cases) of violent action based on a " mirrored narcissistic relationship » in connection with narcissistic grip relationships between a parent and the adolescent, which result in actions on close children, or substitutes for the intrusive parental object. After the fact, it can be deduced that they are however addressed to a third party who could emerge from this questioning of the emotional and social link. His intervention could break this morbid dyadic isolation, so that the work of puberty can finally achieve the change of object of investment and the reduction of the oedipal conflict $[14,15]$.

On the other hand, the tables of « discrepancies » between process levels in the 3 registers: Acts, Family, Sexuality (20 cases) are distributed between:

- Adolescents for whom the process of access to genital sexuality related to their age (S:III) is hampered by environmental conditions " problematic » (8 cases)

- One can declaim a gradient of problems that range from pubertal processes syntones with age, but hindered by unresolved parental conflicts, to inscriptions in psychopathic conduits already installed $[16,17]$.

- Adolescents whose libido is reduced to a child « sexuality » by induced fixations or regressions; (Type S:II), either by regression or by fixation to outdated libidinal modes (9 cases).

A distinction will be made between those for which the infantilizing position established by the parents serves as a back ground for actions related to an adjournment of pubertal thrust. The others present in various capacities perverse polymorphic " modalities » more marked by the dominant aggressiveness in the expression of sexuality, an inability to place them in the object relationship marked by submission, between dependence and rebellion.

- Teenagers faced with pre-objective, archaic problems, but whose modalities of action or elaboration seem more elaborate than pure cases « type » 3 cases)

There are 2 remaining cases of access to genital sexuality that may present problematic acts that could also be included in the variations of adolescent « normal sexuality » (type III) [18-20].

\section{Conclusion}

We can certainly make a typology of sexual assaults, depending on the type of victim or the mode of operation, but it seems to us abusive to infer a typology of the aggressors. Some seem to function psychically homogeneously with the acts they commit and the environment in which they operate. But most of the time, case studies show that the link between the offense and «morbid personality» is much more complex. As we have seen in the discordant problems in the field of the act, sexuality and family functioning, the three levels of psychic functioning, primary secondary and tertiary, allow us to locate ourselves in the different psychic configurations and focus their management [21]. They are not unique and permanent in all subjects or in all cases of family figures but can combine depending on the circumstances. Similarly, none of the family configurations are strictly isolatable from one another, but several " attitudes » can coexist or take turns in a particular family context. This should not cause us to neglect the advantages that can be derived from this " division ", especially in the way of approaching behaviors by referring them to recognizable processes, and therefore to give them a specific response in terms of understanding and elaboration in a psychotherapeutic framework that does not ignore them but uses them to enable the Subject to recognize and assume them, or to derive from them « from the top » by adopting less elementary functionalities.

\section{References}

1. Lemitre S (2010) Clinical and criminological profiles of teenagers AAS in Sexual violence. In: Coutanceau R, Smith J (Eds.), Dunod, France.

2. Raoult PA (2012) Figures of the adolescent perpetrator of sexual assaults in sexual violence in minors. In: Ciavaldini A (Ed.), France, pp: 43-82.

3. Gravier B (2012) Sexual Offense: the clinic is not soluble in criminal law in Sex and Standards. In: Adam $\mathrm{CH}$, de Fraene D, Mary PH, Nagels C, Smeets S (Eds.), Brussels 


\section{Mental Health \& Human Resilience International Journal}

Belgium, Brylant, pp: 59-75.

4. Freud S (1895) Sketch of a scientific psychology in Birth of psychoanalysis. Paris PUF, pp: 307-396.

5. Deledalle G (1978) Charles S Peirce. Writings in Paris Seuil, France.

6. Green A (1998) Private madness. Case-limit analysis, In: Gallimard G (Ed.), Paris NRF, pp: 1-410.

7. Lacan J (1974-1975) R.S.I. seminar Edition of the International Lacanian Association of Psychoanalysis. Paris.

8. Savinaud C (2018) The teenage sexual abuse actor psychoanalytic Clinic. L'Harmattan, France, pp: 1-320.

9. Freud S (1909) L'Homme aux rats journal of an analysis. Paris PUF, pp: 1-286.

10. Aulagnier P (1979) Destiny of pleasure. Paris PUF.

11. Lemay M (1973) Juvenile Psychopathology, Paris, France, pp: 1-662.

12. Lacan J (1949) Aggression in Psychoanalysis Writings. Paris Seuil, pp: 101-124

13. Nagy IB, Framo JL (1980) Family psychotherapies. Paris PUF, pp: 1-388.
14. Balier C (2005) Violence in the abyss. Paris PUF.

15. Becker JB, Rathner JC, Kaplan MS (1986) Adolescent sexual offenders: démographic, criminal and sexual histories, and recommendations for reducing futures offenses. Journal of Interpersonal violence 1(4): 431445.

16. Ciavaldini A (1999) Psychopathology of Sexual Abusers. Paris Masson, France.

17. Harrault A, Savinaud C (2015) sexual abuse of adolescents: company history or family history?. France Toulouse Erès, pp: 1-260.

18. Roman P (2012) Sexual violence in adolescence: understand, welcome, warn, Paris. Elsevier, Masson, pp: $1-208$.

19. Saunders EB, Awad GA (1988) Assessment, management and treatment planning formal adolescent sexuals offenders. Am J Orthopsychiatry 58(4): 571-579.

20. Tardif M, Jacob M, Quenneville R, Proulx J (2012) Juvenile sexual delinquency. T.1. Canada Presses, University of Montreal, pp: 1-603.

21. Vizard E, Monck E, Misch P (1995) Child and adolescent sex abuse perpetrators: a revue of the research literature. Journal of Child Psychology and Psychiatry 36(5): 731756. 